\title{
Effect of Camel Milk on Blood Sugar and Lipid Profile of Patients With Type 2 Diabetes: A Pilot Clinical Trial
}

\author{
Hanieh Sadat Ejtahed ${ }^{1}$; Amir Niasari Naslaji ${ }^{2}$; Parvin Mirmiran ${ }^{1,3}$; Maryam Zraif Yeganeh ${ }^{1}$; \\ Mehdi Hedayati ${ }^{4}$; Fereidoun Azizi ${ }^{5,} ;$ Aliakbar Moosavi Movahedi $^{6}$ \\ ${ }^{1}$ Obesity Research Center, Nutrition and Endocrine Research Center, Research Institute for Endocrine Sciences, Shahid Beheshti University of Medical Sciences, Tehran, IR Iran \\ ${ }_{3}^{2}$ Department of Theriogenology, Faculty of Veterinary Medicine, University of Tehran, Tehran, IR Iran \\ ${ }^{3}$ Department of Clinical Nutrition and Dietetic, Faculty of Nutrition Sciences and Food Technology, National Nutrition and Food Technology Research Institute, Shahid Beheshti \\ University of Medical Sciences, Tehran, IR Iran \\ University of Medical Sciences, Tehran, IR Iran 4 Cellular and Molecular Endocrine Research Center, Research Institute for Endocrine Sciences, Shahid Beheshti University of Medical Sciences, Tehran, IR Iran \\ ${ }^{5}$ Endocrine Research Center, Research Institute for Endocrine Sciences, Shahid Beheshti University of Medical Sciences, Tehran, IR Iran \\ 6 Institute of Biochemistry and Biophysics, University of Tehran, Tehran, IR Iran \\ ${ }^{*}$ Corresponding author: Fereidoun Azizi, Endocrine Research Center, Research Institute for Endocrine Sciences, Shahid Beheshti University of Medical Sciences, Tehran, IR Iran. Tel: \\ +98-2122409309, Fax:+98-2122402463, E-mail: azizi@endocrine.ac.ir
}

Received: June 14, 2014; Revised: August 25, 2014; Accepted: August 31, 2014

\begin{abstract}
Background: It has been shown that camel milk consumption has a definite decreasing effect on the prevalence of diabetes. However, most of these studies were conducted on patients with type 1 diabetes, whereas studies on patients with type 2 diabetes mellitus (T2DM) are limited. In vitro experiments have shown that camel milk was able to decrease blood glucose concentration.

Objectives: The purpose of this study was to investigate effects of camel and cow milk on blood sugar, lipid profile, and blood pressure of patients with T2DM.

Patients and Methods: In a randomized single-blinded controlled clinical trial, 20 patients with T2DM were randomly allocated into two groups. Participants consumed $500 \mathrm{~mL}$ of either camel milk (intervention group) or cow milk(control group) daily for two months. Results: Mean of insulin concentration was significantly increased from 64.59 to $84.03 \mathrm{pmol} / \mathrm{L}$ in the camel milkgroup during the study $(\mathrm{P}$ $<0.05$ ). No significant differences were shown in fasting blood sugar, lipid profile, and blood pressure between the two groups at the end of study. There was significant increase in homeostasis model assessment of insulin resistance(HOMA-IR) during the study in both groups, but no significant difference was seen between the two groups.

Conclusions: Camel milk increased insulin level in patients with T2DM and might contribute to glycemic control in T2DM.
\end{abstract}

Keywords:Camel; Milk; Insulin; Type 2 Diabetes Mellitus

\section{Background}

Diabetes mellitus (DM) is characterized by hyperglycemia resulting from defects in insulin secretion, insulin action, or both. The chronic hyperglycemia of DM leads to long-term damages to various organs and multiple abnormalities including inflammation, dyslipidemia, and hypertension (1, 2). Dyslipidemia and hypertension have been identified as risk factors for cardiovascular complications, the primary cause of death in patients with type 2 DM (T2DM) $(1,3,4)$. Over the years, many types of traditional food treatments and natural remedies have been used to treat $\operatorname{DM}(5,6)$. However, validity and effectiveness of just a few of them have been evaluated; recently, World Health Organization (WHO) has recommended that these traditional food treatments warrant further evaluation to confirm their proposed health benefits (7). Camel milk is traditionally used as a treatment for diseases such as dropsy, jaundice, tuberculosis, asthma, and leishmaniasis in different regions of the world including India, Sudan, and Saudi Arabia (8). Recently, camel milk was also reported to have other potential therapeutic properties such as anticarcinogenic, antimicrobial, antioxidant, angiotensin I-converting enzyme-inhibitory activities, hypocholesterolemic, hypoglycemic, and hypoallergenic effects due to the presence of bioactive compounds in milk (8-14). In India, it has been shown that camel milk consumption has a definite effect on the low prevalence of diabetes in Raica community (15). In vitro experiments have shown that camel milk was able to decrease blood glucose concentration via possible mechanisms among which are containing insulin-like small molecules that mimic insulin interaction with its receptor or presenting insulin in indigestible nanoparticles and transporting this hormone into the bloodstream $(8,16)$. The hypoglycemic potential of camel milk has also been evaluated in patients with DM(9,17-19). However, most of these studies were conducted on patients with type $1 \mathrm{DM}$, whereas studies on patients with T2DM are limited $(20,21)$. Although the cholesterol-lowering activity of camel milk has been

Copyright (C) 2015, Research Institute For Endocrine Sciences and Iran Endocrine Society. This is an open-access article distributed under the terms of the Creative Commons Attribution-NonCommercial 4.0 International License (http://creativecommons.org/licenses/by-nc/4.0/) which permits copy and redistribute the material just in noncommercial usages, provided the original work is properly cited. 
reported in rats $(10,12)$, the hypocholesterolemic mechanism of camel milk is still unclear (8). Moreover, angiotensin 1-converting enzyme (ACE)-inhibitor peptides are present in camel milk proteins, especially in fermented camel milk (13). Lactobacillus helveticus was used extensively to release the ACE-inhibitor peptides from camel milk proteins (13).

\section{Objectives}

Since studies on the effect of camel milk on T2DM are limited, we performed the present study as a pilot experiment to assess the effects of camel milk on blood sugar, lipid profile, and blood pressure of patients with T2DM.

\section{Patients and Methods}

\subsection{Subjects}

This single-blinded, parallel, randomized pilot clinical trial was conducted from November 2012 to March 2013. We selected patients with T2DM with 20 to 70 years of age, who were on diet or oral hypoglycemic agents, from the Endocrine Clinic of Taleghani Hospital, Tehran, Iran. Recruitment was done via telephone and advertisements. Patients with following conditions were excluded: pregnant or lactating women, smokers, requiring insulin injections, using alcohol, body mass index (BMI) $>35 \mathrm{Kg} /$ $\mathrm{m}^{2}$, lactose intolerance, estrogenic drugs or corticosteroids consumption, cardiovascular, liver, lung, or kidney diseases, chronic gastrointestinal or thyroid dysfunctions, changing medication during the study period, following weight loss diets, and having weight changes $>5$ $\mathrm{kg}$ during the two months prior to the study. Sample size was determined for fasting blood sugar (FBS). For an expected change of $2.22 \mathrm{mmol} / \mathrm{L}$ between intervention and control groups and by considering $\alpha=0.05$ and a power of $80 \%$, the sample size was calculated at nine subjects in each group. This number was increased to compensate for the anticipated dropout rate. Written informed consents were obtained from subjects prior to the trial. The study protocol was approved by the Ethics Committee of the Research Institute for Endocrine Sciences, Shahid Beheshti University of Medical Sciences, and was conducted according to the stated principles in the Declaration of Helsinki. This trial was registered in the Iranian Registry of Clinical Trials (IRCT) with the following identification number: IRCT201302044794N7.

\subsection{Study Design}

Eligible participants were randomly allocated to two groups using a block randomization procedure with matched subjects in each block based on sex. Intervention and control groups consisted of 11 and 10 patients, respectively. For a period of two months, patients had daily consumption of $500 \mathrm{~mL}$ of camel milk (intervention group) or $500 \mathrm{~mL}$ of cow milk (control group). Partici- pants were instructed to consume $250 \mathrm{~mL}$ of milk in the morning and $250 \mathrm{~mL}$ in the afternoon for two months. Moreover, all participants were instructed to maintain their usual dietary habits and lifestyle, to avoid consuming any milk other than that provided to them by the researchers, and if possible, to avoid any changes in medication during study period. The participants were not aware of treatment assignments and the camel and cow milk containers were identical. Camel milk was collected from healthy milking camels without observable clinical signs of mastitis. Five minutes prior to milking, camel received oxytocin (20 IU, IM), the nipple was washed, and the camel calf was released to stimulate the dam. After discarding the first few squirts of milk, the milk was collected into clean container. Camel milk was pasteurized at $70^{\circ} \mathrm{C}$ for 15 minutes, preserved in a refrigerator at $4^{\circ} \mathrm{C}$, and distributed weekly by the researchers. Milks were sampled and their compositions were analyzed at the beginning of the study in the Tohid laboratory, Tehran, Iran. All experiments were done in duplicate. Results of analysis showed that camel milk and cow milk were not significantly different in protein, fat, and lactose contents (Table 1). Compliance with the milk consumption guidelines and probable adverse reactions were monitored via phone interviews once a week.

Table 1. Protein, Fat, and Lactose Content of the Camel and Cow Milks Used in This Study

\begin{tabular}{lcc}
\hline Variables $^{\mathrm{a}}$ & Camel Milk & Cow Milk \\
\hline Protein & 2.8 & 3.2 \\
Fat & 3.0 & 2.5 \\
Lactose & 4.5 & 4.8 \\
\hline
\end{tabular}

a All of the values are present as No. (\%).

\subsection{Anthropometric, Dietary, and Biochemical Measurements}

Patients' general and medical histories were obtained by trained questioners. All biochemical, anthropometric, and dietary indices were measured at baseline and after two months (at the end of the intervention). Information on consumed oral hypoglycemic agents of two groups was collected at the beginning of the trial. Body weight was measured and rounded to the nearest $100 \mathrm{~g}$ using an analog scale (Seca, Hamburg, Germany) while the subjects were minimally clothed and had no shoes on. Height was measured and rounded to the nearest $0.5 \mathrm{~cm}$ in a standing position without shoes, using a Seca stadiometer. BMI was calculated with the following equation: BMI = wight $(\mathrm{kg}) /$ square of height $\left(\mathrm{m}^{2}\right)$. Blood pressure was measured by a digital sphygmomanometer (SANITAS, Germany) after a 15-minutes rest in sitting position. Dietary intakes were estimated using 24-hour dietary recall for three days. Three-day averages of energy and macronutrients intakes were analyzed by Nutritionist 4 soft- 
ware (First Databank Inc., Hearst Corp., San Bruno, CA). All data entry was performed by trained dietitians. For measuring FBS, insulin, total cholesterol (TC), triglyceride (TG), high-density lipoprotein cholesterol (HDL), and low-density lipoprotein cholesterol (LDL), $5 \mathrm{~mL}$ of blood was collected after 10 to 12 hours of fasting. FBS and TG were measured by using Colorimetric Enzymatic method with commercially available Parsazmun kits (Tehran, Iran). Serum TC, HDL, and LDL were measured using Enzymatic Photometric method with Parsazmun kits (Tehran, Iran). Insulin concentration was measured using the enzyme-linked immunosorbent assay (ELISA) with Mercodia kits (Uppsala, Sweden). Intra-assay and Inter-assay coefficients of variations were respectively $2.1 \%$ and $1.9 \%$ for FBS, $1.0 \%$ and $1.4 \%$ for TC, 3.4\% and 3.3\% for TG, $0.8 \%$ and $1.3 \%$ for LDL, $4.5 \%$ and $3.7 \%$ for HDL, and $4.9 \%$ and $4.2 \%$ for insulin. Insulin resistance was calculated by the homeostasis model assessment of insulin resistance (HOMA-IR) equation:

HOMA-IR $=[\mathrm{FBS}(\mathrm{mg} / \mathrm{dL}) \times$ Fasting Inulin concentration $(\mathrm{mU} / \mathrm{L}) / 405$

\subsection{Statistical Analysis}

All statistical analyses were performed using SPSS 16.0 (SPSS Inc., Chicago, IL, USA). The normality of the distributions of variables was assessed by the KolmogorovSmirnov and the Shapiro-Wilk tests. Independent-samples t-test, Fisher's exact test, and Mann-Whitney U test were used for comparing the baseline characteristics and dietary intakes between the two groups. Changes in dietary intakes between the beginning and end of the trial within each group were compared using Wilcoxon test. Analysis of covariance (ANCOVA) was used to identify any significant differences between study groups after intervention, adjusting for baseline measurements. The changes in biochemical measurements of the participants between the beginning and end of the trial were compared by paired-samples t-test within each group. $\mathrm{P}$ $<0.05$ was considered statistically significant.

\section{Results}

Twenty participants completed the two-month trial and were included in the statistical analysis. One female dropped out of study, stating a loss of interest as the reason for discontinuing the study (Figure 1). The acceptability of both cow and camel milks was nearly good. Only two patients in the intervention group complained of flatulence and cramping and one in the control group reported flatulence and diarrhea. As shown in Table 2, there were no significant differences in baseline characteristics between study groups. Among 20 patients who participated in this study, $36.4 \%$ of those in camel milk group and $22.2 \%$ of those in cow milk group were male. Mean ages of participants in the camel and cow milk groups were 53.0 and 50.9 years, respectively. Ten patients in camel milk group and three patients in cow milk group took metformin and glibenclamide simultaneously. One patient in camel milk group and four patients in cow milk group took only metformin and two patients in cow milk group consumed no oral drugs. There was no significant difference in consumed oral hypoglycemic agents between two groups. Weight remained unchanged during the study in both groups. The dietary intakes of participants throughout the study are shown in Table 3. Data showed a significant difference in dietary intake of monounsaturated fatty acids (MUFA) between the two groups just before the study $(\mathrm{P}<0.05)$. In the cow milk group, dietary intakes of MUFA, calcium (Ca), and phosphorous (P) increased significantly. Compared to the baseline values, dietary intakes of saturated fatty acids (SFA), Ca, and P increased significantly after the intervention period in the camel milk group $(\mathrm{P}<0.05)$. At the end of intervention, the amounts of energy consumption showed no significant increases in either group in comparison with baseline. At the end of the study, no statistically significant differences in dietary intakes were observed between study groups. No statistically significant differences existed in biochemical variables between the cow and camel milks groups at baseline. Results of ANCOVA showed no statistically significant differences between two groups at the end of study, adjusted for baseline values. Insulin concentration was significantly increased in the camel milk group in comparison to the baseline values $(\mathrm{P}<0.05)$. Moreover, there was significant increase in HOMA-IR during the study in both groups $(P<0.05)$ although HOMA-IR was not statistically different between two groups at the end of study. A significant reduction was shown in systolic blood pressure only in the cow milk group (Table 4 ).

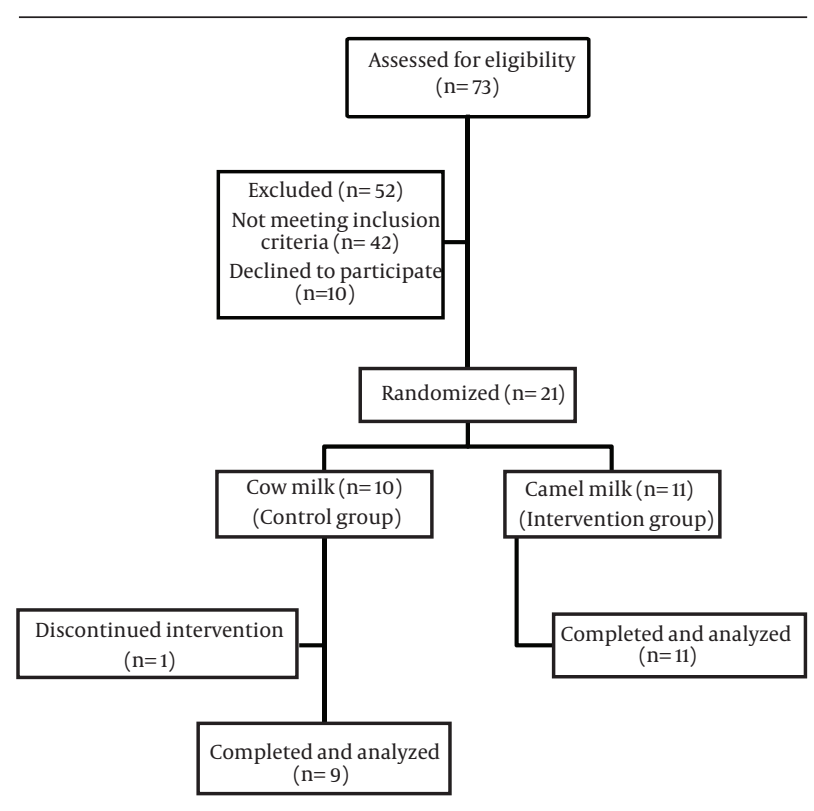

Figure 1. Flowchart for Screening and Enrolment of Participants 
Ejtahed HS et al.

\begin{tabular}{|c|c|c|}
\hline Variables & Camel Milk $(n=11)$ & $\operatorname{Cow} \operatorname{Milk}(\mathbf{n}=9)$ \\
\hline Age, y & $53.0 \pm 7.1$ & $50.9 \pm 12.9$ \\
\hline Men/Women & $4 / 7$ & $2 / 7$ \\
\hline BMI, kg/m² & $27.8 \pm 4.5$ & $31.1 \pm 3.9$ \\
\hline $\begin{array}{l}\text { Duration of Diabe- } \\
\text { tes, } y\end{array}$ & $8.4 \pm 7.9$ & $5.9 \pm 4.1$ \\
\hline $\begin{array}{l}\mathrm{a} \text { Abbreviation: BMI, bo } \\
\mathrm{b}_{\text {Data are presented as }} \\
{ }^{\mathrm{C}} \text { No significant differe } \\
\text { samples t-test, Fisher's }\end{array}$ & $\begin{array}{l}\text { mass index. } \\
\text { eans } \pm \text { SD or No. } \\
\text { e between groups at bas } \\
\text { ct test, and Mann-Whitn }\end{array}$ & $\begin{array}{l}\text { eline (Independent- } \\
\text { ey U test). }\end{array}$ \\
\hline
\end{tabular}

Table 3. Dietary Intakes of Participants at Baseline and After Intervention ${ }^{\mathrm{a}}$

\begin{tabular}{|c|c|c|}
\hline Variables & $\begin{array}{c}\text { Camel Milk } \\
(\mathbf{n}=\mathbf{1 1})\end{array}$ & $\begin{array}{c}\text { Cow Milk } \\
(\mathbf{n}=\mathbf{9})\end{array}$ \\
\hline \multicolumn{3}{|l|}{ Energy, kcal } \\
\hline Baseline & $1645 \pm 481$ & $1337 \pm 549$ \\
\hline After Intervention & $1934 \pm 709$ & $1553 \pm 510$ \\
\hline \multicolumn{3}{|l|}{ Carbohydrate, g } \\
\hline Baseline & $258 \pm 132$ & $213 \pm 93$ \\
\hline After Intervention & $249 \pm 54$ & $227 \pm 73$ \\
\hline \multicolumn{3}{|l|}{ Protein, $\mathrm{g}$} \\
\hline Baseline & $70.6 \pm 29.4$ & $49.1 \pm 20.0$ \\
\hline After Intervention & $102 \pm 104$ & $66.6 \pm 28.7$ \\
\hline \multicolumn{3}{|l|}{ Total Fat, $g$} \\
\hline Baseline & $48.4 \pm 15.1$ & $35.3 \pm 15.0$ \\
\hline After Intervention & $60.5 \pm 26.0$ & $44.6 \pm 17.6$ \\
\hline \multicolumn{3}{|l|}{ Saturated Fat, g } \\
\hline Baseline & $12.2 \pm 5.1$ & $9.9 \pm 6.6$ \\
\hline After Intervention & $18.4 \pm 8.0^{b}$ & $14.2 \pm 2.2$ \\
\hline \multicolumn{3}{|c|}{ Monounsaturated Fat, g } \\
\hline Baseline & $15.6 \pm 6.9$ & $8.9 \pm 3.7^{c}$ \\
\hline After Intervention & $19.9 \pm 10.8$ & $14.6 \pm 5.3^{b}$ \\
\hline \multicolumn{3}{|c|}{ Polyunsaturated Fat, g } \\
\hline Baseline & $13.3 \pm 4.4$ & $12.4 \pm 4.6$ \\
\hline After Intervention & $11.2 \pm 5.1$ & $10.5 \pm 11.4$ \\
\hline \multicolumn{3}{|l|}{ Dietary Fiber, g } \\
\hline Baseline & $16.9 \pm 9.4$ & $17.5 \pm 7.7$ \\
\hline After Intervention & $13.1 \pm 4.5$ & $14.0 \pm 5.6$ \\
\hline \multicolumn{3}{|l|}{ Calcium, mg } \\
\hline Baseline & $644 \pm 314$ & $505 \pm 338$ \\
\hline After Intervention & $1207 \pm 395^{b}$ & $1108 \pm 301^{b}$ \\
\hline \multicolumn{3}{|l|}{ Phosphorus, mg } \\
\hline Baseline & $750 \pm 298$ & $606 \pm 286$ \\
\hline After Intervention & $1335 \pm 847^{\mathrm{b}}$ & $1073 \pm 308^{b}$ \\
\hline \multicolumn{3}{|c|}{$\begin{array}{l}\text { a Data are presented as means } \pm \text { SD. } \\
b_{\text {Significant difference within group throughout the study }(\mathrm{P}<0.05 \text {, }} \\
\text { Wilcoxon). } \\
{ }^{c} \text { Significant difference between groups at baseline }(P<0.05 \text {, Mann- } \\
\text { Whitney U). }\end{array}$} \\
\hline
\end{tabular}

\section{Discussion}

Natural foods with antihyperglycemic properties are being used increasingly by patients with DM. Some studies have reported that camel milk might be able to improve the glycemic control of patients with DM. Hence, the present study was designed to investigate the effects of two-month camel milk consumption on the blood sugar, lipid profile, and blood pressure of patients with T2DM. It was shown that camel milk consumption significantly increased insulin concentration during the study. However, HOMA-IR increased in both groups and FBS and lipid profile changes were not statistically significant. Systolic blood pressure decreased significantly in cow milk group. In the present study, no change in weight was noted within any group during the study. Increased intakes of energy and protein were observed in both groups, which were not statistically significant. Therefore, the observed changes in variables could not be due to the changes in weight and dietary intakes. According to our knowledge, this study is the first randomized clinical trial investigating the effects of camel milk consumption in comparison with cow milk consumption in patients with T2DM. We intended to investigate whether consumption of camel milk was superior to consumption of cow milk in patients with T2DM. In previous studies, most of which were conducted on patients with type $1 \mathrm{DM}$, patients in the control group consumed no milk. Agrawal et al. in repeated trials observed that daily consumption of $500 \mathrm{~mL}$ of camel milk had lowered the plasma glucose of patients with type $1 \mathrm{DM}$ and the daily doses of insulin injection was reduced by $30 \%$ to $35 \%(9,19,22,23)$. Al-Numair reported that treatment with camel milk restored the plasma glucose and insulin levels to near normal in streptozocin-type 2 diabetic rats (10). Our results are in accordance with the findings of Wang et al. and Agrawal et al., which have respectively shown that 14 -week and three-months camel milk consumption had improved insulin levels of patients with T2DM $(20,21)$. On the other hand, these studies documented that camel milk could decrease FBS and HOMA-IR. However, this study did not support the blood sugar-lowering potential of camel milk. These inconsistent findings could be partly because of variations in camel milk composition, differences in duration of treatment periods, sample size, and clinical characteristics of participants. Variations observed in the camel milk composition in different studies could be attributed to several factors such as different analytical procedures, geographical locations, seasonal variations, feeding conditions, stage of lactation, and breed of camel (24). Some mechanisms for lowering sugar concentration by camel milk consumption have been proposed, one of which is the higher level of insulin in camel milk in comparison to milk from other animals. Furthermore, insulin in camel milk is encapsulated in nanoparticles, which are capable of transporting this hormone intact into the bloodstream (16). Camel milk has unique properties including not coagulating easily at low $\mathrm{pH}$, having 
Table 4. Effects of Camel Milk and Cow Milk Consumption on Biochemical Variables in Patients With Type 2 Diabetes $a, b, c$

\begin{tabular}{lcc}
\hline Variables & $\begin{array}{c}\text { Camel milk } \\
(\mathbf{n}=\mathbf{1 1})\end{array}$ & $\begin{array}{c}\text { Cow milk }(\mathbf{n} \\
\mathbf{= 9})\end{array}$ \\
\hline Fasting blood sugar, mmol/L & & \\
\hline Baseline & $9.38 \pm 2.83$ & $8.05 \pm 2.39$ \\
\hline $\begin{array}{l}\text { After Intervention } \\
\text { Insulin, pmol/L }\end{array}$ & $9.44 \pm 2.55$ & $8.94 \pm 3.22$ \\
\hline $\begin{array}{l}\text { Baseline } \\
\text { After Intervention }\end{array}$ & $64.59 \pm 79.17$ & $61.81 \pm 39.59$ \\
\hline
\end{tabular}

HOMA-IR

\begin{tabular}{|lcc|}
\hline Baseline & $3.4 \pm 2.9$ & $3.0 \pm 2.4$ \\
\hline After Intervention & $4.7 \pm 3.6^{\mathrm{d}}$ & $4.0 \pm 2.3^{\mathrm{d}}$ \\
\hline Total cholesterol, mmol/L & & \\
\hline Baseline & $4.82 \pm 1.01$ & $4.90 \pm 0.83$ \\
\hline After Intervention & $4.71 \pm 1.11$ & $5.23 \pm 1.40$ \\
\hline Triglycerides, mmol/L & & \\
\hline Baseline & $1.58 \pm 0.58$ & $1.73 \pm 0.64$ \\
\hline After Intervention & $1.58 \pm 0.59$ & $1.97 \pm 0.98$ \\
\hline HDL-C, mmol/L & & \\
\hline Baseline & $1.22 \pm 0.26$ & $1.27 \pm 0.31$ \\
\hline After Intervention & $1.30 \pm 0.31$ & $1.30 \pm 0.28$ \\
\hline LDL-C, mmol/L & & \\
\hline Baseline & $2.75 \pm 0.75$ & $2.69 \pm 0.49$ \\
\hline After Intervention & $2.67 \pm 0.83$ & $3.03 \pm 0.83$ \\
\hline $\begin{array}{l}\text { Systolic Blood Pressure, } \\
\text { mmHg }\end{array}$ & & \\
\hline Baseline & $135 \pm 13$ & $132 \pm 17$ \\
\hline After Intervention & $132 \pm 20$ & $122 \pm 19^{\mathrm{d}}$ \\
\hline
\end{tabular}

Diastolic Blood Pressure, mmHg

\begin{tabular}{lcc} 
Baseline & $86 \pm 14$ & $83 \pm 7$ \\
After Intervention & $84 \pm 15$ & $79 \pm 10$ \\
\hline
\end{tabular}

a Abbreviations: HOMA-IR, homeostatic model assessment-insulin resistance; HDL-C, high-density lipoprotein cholesterol; and LDL-C, lowdensity lipoprotein cholesterol.

$\mathrm{b}$ Data are presented as means $\pm \mathrm{SD}$.

c No Significant difference was seen between two groups ( $P>0.05$, analysis of covariance, adjusted for baseline values).

$\mathrm{d}$ Significant difference within group throughout the study $(\mathrm{P}<0.05$, paired-samples t-test).

good buffering capacity, having different proportions of caseins and fatty acids, and making larger lipid micelles, which protect it from digestion by pepsin in the stomach $(8,16)$. Moreover, camel milk contains insulin-like small molecules that mimic insulin interaction with its receptor $(8,16)$. The antidiabetic activity of camel milk might be explained by its immunomodulatory functions on the $\beta$ cells of pancreas, anti-inflammatory effect, and high concentration of antioxidants $(18,25)$. DM is associated with profound alterations in lipid profile and blood pres- sure and an increased risk of cardiovascular disease. A review of some studies suggested that camel milk could alleviate the risk of cardiovascular diseases by its bioactive compounds (8) but the present study did not support the cholesterol-lowering potential of camel milk. Agrawal et al. in a three-month clinical trial showed that daily consumption of $500 \mathrm{~mL}$ of camel milk in combination with usual care caused no changes in lipid profile of patients with type 1 DM (9), which was in agreement with the results of our study. However, Kotb-El-Sayed in a study on patients with type 1 DM demonstrated that significant decrease in lipid profile was shown in both camel milk and control groups (18). Al-Numair reported that camel milk had TC and TG lowering properties in type 2 diabetic rats (10). Wang et al. in another study, showed that camel milk decreased TG and TC in patients with T2DM (20). These inconsistent results suggest that further investigation on this issue is needed. It was proposed that probiotic bacteria-fermented camel milk has peptides with ACE inhibitory activity and could be effective in blood pressure control (8). However, in the present study, in which pasteurized raw camel milk was utilized, no significant change in blood pressure was seen in the camel milk group. On the other hand, systolic blood pressure decreased in the cow milk group during the study. Further studies on the effects of fermented camel milk by lactic acid bacteria in patients with DM are recommended. The limitations of this study included its short duration and small sample size. Further investigations with longer duration and larger sample sizes are needed for definitive conclusions about the effects of camel milk on T2DM. Lack of glycosylated hemoglobin (HbAic) measurement was another limitation of our study. Since HbAlc measures average blood glucose level over a prolonged period, we could not give an indication of longer-term blood glucose control in this study.

In conclusion, this trial showed that although consumption of camel milk could increase serum insulin concentration in patients with T2DM, FBS, lipid profile, and blood pressure changes in the camel milk group were not statistically significant in comparison with the cow milk group. These results suggest that camel milk might help control insulin level in patients with T2DM.

\section{Acknowledgements}

The authors wish to acknowledge Ms. Niloofar Shiva for critical editing of English grammar and syntax of the manuscript.

\section{Authors' Contributions}

Hanieh-Sadat Ejtahed: design of the study, collection, analysis and interpretation of data, drafting of manuscript, and approval of the final version of the manuscript; Amir Niasari Naslaji: conception and design of the study and approval of the final version of the manuscript; Parvin Mirmiran: design of the study, revision of 
manuscript, and approval of the final version of the manuscript; Maryam Zraif Yeganeh: collection of data, drafting of manuscript, and approval of the final version of the manuscript; Mehdi Hedayati: interpretation of data and approval of the final version of the manuscript; Fereidoun Azizi: conception and design of the study, revision of manuscript, and approval of the final version of the manuscript; and Aliakbar Moosavi Movahedi: revision of manuscript and approval of the final version of the manuscript.

\section{Funding/Support}

This work was funded by the Research Institute for Endocrine Sciences, Shahid Beheshti University of Medical Sciences, IR Iran.

\section{References}

1. Ray A, Huisman MV, Tamsma JT, Writing G, van Asten J, Research., et al. The role of inflammation on atherosclerosis, intermediate and clinical cardiovascular endpoints in type 2 diabetes mellitus. Eur J Intern Med. 2009;20(3):253-60.

2. Sourij H, Schmoelzer I, Dittrich P, Paulweber B, Iglseder B, Wascher TC. Insulin resistance as a risk factor for carotid atherosclerosis: a comparison of the Homeostasis Model Assessment and the short insulin tolerance test. Stroke. 2008;39(4):1349-51.

3. Ali YS, Linton MF, Fazio S. Targeting cardiovascular risk in patients with diabetes: management of dyslipidemia. Curr Opin Endocrinol Diabetes Obes. 2008;15(2):142-6.

4. Kokubo Y. Associations of impaired glucose metabolism and dyslipidemia with cardiovascular diseases: what have we learned from Japanese cohort studies for individualized prevention and treatment? EPMAJ. 2011;2(1):75-81.

5. Leiherer A, Mundlein A, Drexel H. Phytochemicals and their im pact on adipose tissue inflammation and diabetes. Vascul Pharmacol. 2013;58(1-2):3-20.

6. Rudkowska I. Functional foods for health: focus on diabetes. Maturitas. 2009;62(3):263-9.

7. World Health Organization.. WHO Expert Committee on Diabetes Mellitus: second report. World Health Organ Tech Rep Ser. 1980;646:1-80.

8. Al haj OA, Al Kanhal HA. Compositional, technological and nutritional aspects of dromedary camel milk-A review. Int Dairy J. 2010:1-11.

9. Agrawal PP, Swami SC, Beniwal R, Kochar DK, Sahani MS, Tuteja FC. Effect of camel milk on glycemic control, risk factors and diabetes quality of life in type-1 diabetes: A randomised prospective controlled study.J Camel Pract Res. 2003;10(1):45-50.
10. Al-Numair KS. Type II diabetic rats and the hypolipidemic effect of camel milk. J Food Agric Environ. 2010;8(2):77-81.

11. Korish AA, Arafah MM. Camel milk ameliorates steatohepatitis, insulin resistance and lipid peroxidation in experimental non-alcoholic fatty liver disease. BMC Complement Altern Med.2013;13:264

12. E. Sulieman AM, A. Elayan A, Saleh FA. The Hypocholesterolemic Effect of Gariss and Gariss Containing Bifidobacteria in Rats Fed on a Cholesterol-Enriched Diet. Asian J Biochem. 2008;3(1):43-7.

13. Quan S, Tsuda H, Miyamoto T. Angiotensin I-converting enzyme inhibitory peptides in skim milk fermented withLactobacillus helveticus130B4 from camel milk in Inner Mongolia, China. J Sci Food Agric. 2008;88(15):2688-92.

14. Sboui A, Khorchani T, Djegham M, Agrebi A, Elhatmi H, Belhadj O. Anti-diabetic effect of camel milk in alloxan-induced diabetic dogs: a dose-response experiment. J Anim Physiol Anim Nutr (Berl). 2010;94(4):540-6.

15. Agrawal RP, Budania S, Sharma P, Gupta R, Kochar DK, Panwar RB et al. Zero prevalence of diabetes in camel milk consuming Raica community of north-west Rajasthan, India. Diabetes Res Clin Pract. 2007;76(2):290-6.

16. Malik A, Al-Senaidy A, Skrzypczak-Jankun E, Jankun J. A study of the anti-diabetic agents of camel milk. Int JMol Med.2012;30(3):585-92.

17. Mohamad RH, Zekry ZK, Al-Mehdar HA, Salama O, El-Shaieb SE, ElBasmy AA, et al. Camel milk as an adjuvant therapy for the treatment of type 1 diabetes: verification of a traditional ethnomedical practice. J Med Food. 2009;12(2):461-5.

18. Kotb-El-Sayed MI, Al-Shoeibi ZY, Abd El-Ghany AA, Atef ZA. Effects of Camels Milk as a Vehicle for Insulin on Glycaemic Control and Lipid Profile in Type 1 Diabetics. Am J Biochem Biotechnol . 2011;7(4):179-89.

19. Agrawal RP, Jain S, Shah S, Chopra A, Agarwal V. Effect of camel milk on glycemic control and insulin requirement in patients with type 1 diabetes: 2-years randomized controlled trial. Eur J Clin Nutr. 2011;65(9):1048-52.

20. Wang SY, Liang JP, Song NN, Shao WJ, Heng H. Effect of raw camel milk in type 2 diabetes animal models and patients: ten months randomised study. J Camel Prac Res. 2009;16(1):107-13.

21. Agrawal RP, Sharma P, Gafoorunissa SJ, Ibrahim SA, Shah B, Shukla DK, et al. Effect of camel milk on glucose metabolism in adults with normal glucose tolerance and type 2 diabetes in Raica community: a crossover study. Acta Biomed. 2011;82(3):181-6.

22. Agrawal RP, Tantia P, Jain S, Agrawal R, Agrawal V. Camel milk: a possible boon for type 1 diabetic patients. Cell Mol Biol (Noisy-legrand). 2013;59(1):99-107.

23. Agrawal RP, Dogra R, Mohta N, Tiwari R, Singhal S, Sultania S. Beneficial effect of camel milk in diabetic nephropathy. Acta Biomed. 2009;80(2):131-4.

24. Khaskheli M, Arian MA, ChaudhryS, Soomro AH, Qureshi TA. Physico-chemical quality of camel milk. J Agric Soc Sci. 2005;2:164-6.

25. Korish AA. The antidiabetic action of camel milk in experimental type 2 diabetes mellitus: an overview on the changes in incretin hormones, insulin resistance, and inflammatory cytokines. Horm Metab Res. 2014;46(6):404-11. 